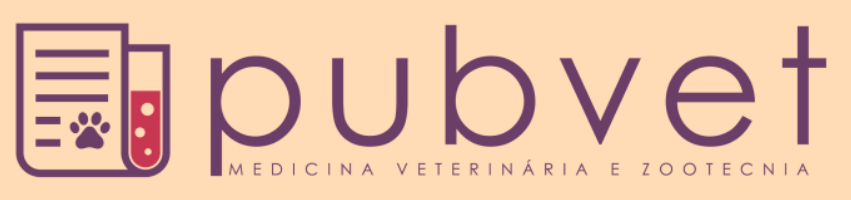

https://doi.org/10.22256/pubvet.v12n6a103.1-4

\title{
Carcinoma de células escamosas em orelha de gato: abordagem clínico-cirúrgica em relato de caso
}

\author{
Cleyson Teófilo Braga Filho ${ }^{\bullet} 1^{*}$, Carlos Eduardo Bastos Lopes ${ }^{\bullet}$, Priscila Sales \\ Braga $^{\bullet}{ }^{3}$, Camila Lacerda Soares ${ }^{\bullet} 4$, Daniel de Araújo Viana ${ }^{\oplus 5}$ \\ ${ }^{I}$ Graduado em Medicina Veterinária, Faculdade de Veterinária, Universidade Estadual do Ceará. Fortaleza-CE Brasil. Email: cleysont@ gmail.com \\ ${ }^{2}$ Graduando em medicina veterinária, Faculdade de Veterinária, Universidade Estadual do Ceará. Fortaleza-CE Brasil. Email: 1993carlos.eduardo@ gmail.com \\ ${ }^{3}$ Graduanda em medicina veterinária, Faculdade de Veterinária, Universidade Estadual do Ceará. Fortaleza-CE Brasil. Email: priscilasalesbraga2@ gmail.com \\ ${ }^{4}$ Médica Veterinária, Universidade Estadual do Ceará, Faculdade de Veterinária, Centrode Controle de Zoonoses.Crateús-CE Brasil. Email: camyllalacerda1991@ gmail.com \\ ${ }^{5}$ Pathovet. Anatomia Patológica e Patologia Clínica Veterinária, Fortaleza-CE Brasil.Email: viana.daniel78@gmail.com \\ ${ }^{*}$ Autor para correspondência
}

\begin{abstract}
RESUMO. O carcinoma cutâneo de células escamosas é uma neoplasia maligna epitelial que muito acomete felinos de pele clara, ou os que ressaltam áreas despigmentadas e hipotríquias, tais como orelhas e nariz. Dentre as formas de tratamento, a técnica cirúrgica pode ser um procedimento de eleição, a depender do estadiamento da enfermidade. Este relato tem por objetivo discorrer sobre um caso de carcinoma espinocelular em pavilhão auricular externo de um gato, apresentando cura cirúrgica completa pós-conchectomia em uma detalhada abordagem pré e trans-cirúrgica.
\end{abstract}

Palavras Chave: câncer, carcinoma espinocelular, cirurgia, felino

\section{Squamous cell carcinoma in the ear of cat: a clinical-surgical approach in a case report}

ABSTRACT. The cutaneous squamous cell carcinoma is a malignant epithelial neoplasm of high incidence among felines of clear skin, or those lacking pigment and hair in certain locations, such as ears and nose. Among the treatment strategies, the surgical technique may be the treatment of choice, depending on the staging of the condition. This report aims to discuss about a case of spine cell carcinoma in the pinna of a cat, presenting a complete surgical cure post-conchectomy in a detailed pre and post-surgical approach.

Keywords: cancer, feline, spine cell carcinoma, surgery.

\section{Carcinoma de células escamosas en oreja de gato: enfoque clínico- quirúrgico en reporte de un de caso}

RESUMEN. El carcinoma cutáneo de células escamosas es una neoplasia maligna epitelial que comúnmente afecta a los felinos de piel clara, o los que resaltan áreas despigmentadas e hipotrías, tales como orejas y nariz. Entre las formas de tratamiento, la técnica quirúrgica puede ser un procedimiento de elección, a depender de la estadificación de la enfermedad. Este relato tiene por objetivo discurrir sobre un caso de carcinoma espinocelular en pabellón auricular externo de un gato, presentando cura quirúrgica completa postconquectomía en un detallado abordaje pre y trans-quirúrgico.

Palabras clave: cáncer, carcinoma espinocelular, cirugía, felino 


\section{Introdução}

O carcinoma de células escamosas ou espinocelular, consiste de uma neoplasia originada do estrato espinhoso da epiderme de tecidos epitelizados. Epidemiologicamente, este tumor maligno é um dos mais frequentes na medicina veterinária, sendo comum em cães e gatos (Goldschmidt \& Goldschmidt 2017).

Nos felinos domésticos, representa o tumor mais frequente e, de maneira superior à maioria das outras espécies, a incidência desse câncer se torna mais evidente quando analisados os fatores ambientais e individuais. A constante exposição aos raios solares e a pigmentação animal, bem como as regiões de alopecia parcial ou total e os hábitos individuais são os principais fatores associados à ocorrência do problema e, portanto, sua carcinogênese nessa espécie (Gross et al. 2008; Goldschmidt \& Goldschmidt 2017).

Outros fatores ainda são defendidamente associados à ocorrência do tumor, como a continuidade de lesões inflamatórias crônicas, como a dermatite actínica nas extremidades de animais com pelagem branca (Modiano et al. 1999; Gross et al. 2008), ou mesmo a possível participação viral, como nos casos em que coexiste o Vírus da Imunodeficiência Felina (Modiano et al. 1999), ou ainda a presença de papilomavírus, como demonstrado em cerca de metade dos casos de carcinomas espinocelulares nasais em gatos em estudo específico (Goldschmidt \& Hendrick 2008).

Em pacientes onde a exérese cirúrgica completa da neoplasia é possível, esta é a modalidade terapêutica mais indicada, juntamente com a continuidade do pós cirúrgico com quimioterapia (Withrow et al. 2014). Adicionalmente, outras estratégias têm ganhado espaço, como a eletroquimioterapia reducional (Rangel et al. 2008) e a criocirurgia (Withrow et al. 2014), técnicas possivelmente aliadas. Portanto, o objetivo do presente trabalho é relatar um caso de carcinoma espinocelular em pavilhão auricular externo de um gato, apresentando cura cirúrgica completa pós-conchectomia em uma detalhada abordagem pré e trans-cirúrgica.

\section{Relato de caso}

Foi atendido em uma unidade clínica veterinária particular na cidade de Fortaleza, Ceará, no dia 2 de janeiro de 2018, um felino doméstico macho, adulto, cor clara, sem raça definida, com 4,5 Kg. O animal chegou à clínica apresentando uma lesão ulcerativa, com presença de secreção sero-sanguinolenta e com tecido granulomatoso na face lateral da orelha externa direita (Figura 1). O tutor afirmou que o animal, recém adotado pelo mesmo, não possuía prévio histórico de vermifugação ou vacinação conhecido.

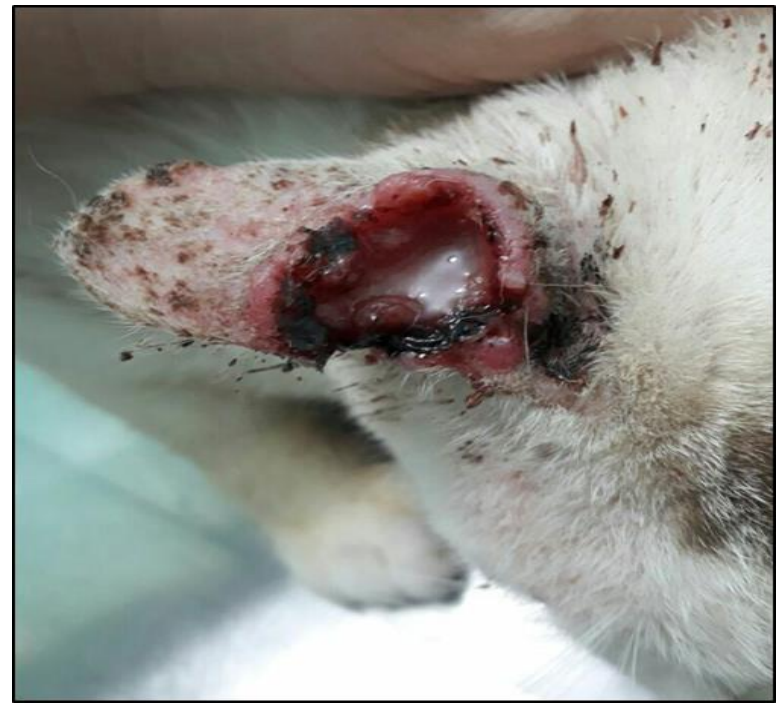

Figura 1. Aspecto macroscópico da lesão em face lateral da orelha externa direita no animal

Durante a anamnese, o animal se encontrava ativo, ingerindo normalmente água e alimentos, apresentando também fezes e urina dentro dos parâmetros da espécie. Ao exame físico, foram constatadas mucosas ocular e oral normocoradas, tempo de preenchimento capilar (TPC) $<2$ segundos, animal hidratado, sem alterações na ausculta cardiopulmonar, assim como na palpação abdominal.

Ao olhar clínico-epidemiológico, ao se suspeitar de carcinoma de células escamosas, o procedimento proposto foi de extirpação do tumor através da conchectomia (Figura 2), com o posterior envio da amostra para confirmação em serviço de histopatologia.

Foram solicitados alguns exames laboratoriais a fim de realizar o procedimento cirúrgico, como hemograma completo e bioquímica sérica (Creatinina, Alanina Aminotransferase e Proteínas Totais).

Após a análise conjunta, o animal foi brevemente encaminhado para cirurgia de conchectomia. O protocolo pré-cirúrgico constou de jejum hídrico e alimentar de 12 horas, antibioticoterapia profilática com penicilina benzatina $(240.000 \mathrm{UI} / \mathrm{kg}$, via intramuscular IM), tramadol $(4 \mathrm{mg} / \mathrm{kg}$, IM), meloxicam $(0,2$ $\mathrm{mg} / \mathrm{kg}$, via subcutânea - SC). Como medicação 
pré-anestésica (MPA) foi utilizado acepromazina a $0,2 \%(0,1 \mathrm{mg} / \mathrm{kg}$, IM). Seguidos 15 minutos da MPA, a indução foi realizada com proporfol $(4 \mathrm{mg} / \mathrm{kg}$, via intravenosa) e a manutenção anestésica foi instituída com isofluorano em circuito semiaberto. A cirurgia foi iniciada incisando-se a cartilagem auricular com margem de segurança para exérese do tumor. Foi feito um plano de sutura simples contínuo no coto da orelha com fio absorvível sintético (Vicryl) número 3-0. Foi prescrito, no pós-operatório, o antiinflamatório Meloxican 0,2\% (0,2 mg/kg, SC) a cada 24 horas durante 5 dias, antibioticoterapia a base de cefalotina $(30 \mathrm{mg} / \mathrm{kg}$, IM) a cada 12 horas durante 5 dias e limpeza da ferida cirúrgica com solução fisiológica e digluconato de Clorexidina.

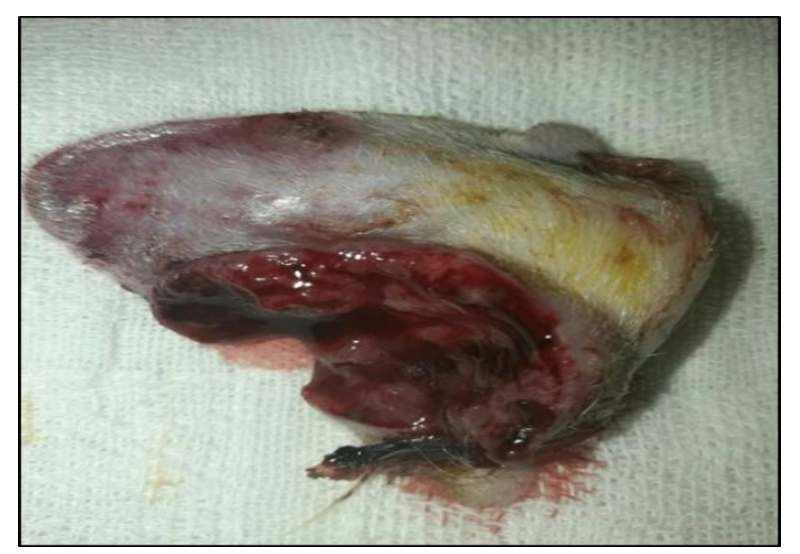

Figura 2. Lesão em base de orelha após a retirada cirúrgica

Posteriormente, para elucidação diagnóstica, bem como graduação tumoral e avaliação de margens cirúrgicas, foi realizado o processamento histopatológico a partir de amostra tecidual préfixada em solução de formalina a $10 \%$, onde foi possível concluir que amostra apresentava um quadro compatível com carcinoma de células escamosas, por apresentar blocos sólidos e irregulares de células neoplásicas malignas, por vezes agrupando-se em densos aglomerados circulares que evidenciam pérolas córneas ocasionais, sendo classificado como de grau 2 (neoplasia moderadamente diferenciada), e apresentando ainda margens laterais e profundas livres da neoplasia (Figura 3).

\section{Discussão}

O CCE consiste numa neoplasia comum em países como o Brasil, de clima tropical, já que a exposição crônica do animal à radiação ultravioleta é um dos principais fatores para o desenvolvimento da doença (Bastos et al. 2017). A pele e o tecido subcutâneo são locais comuns de neoplasia primária em gatos e o carcinoma de células escamosas, em particular extremidades das orelhas e do nariz (Gross et al. 2009). No presente relato, o felino apresentava a região auricular comprometida pela presença da massa tumoral, apresentando lesões típicas dessa enfermidade.

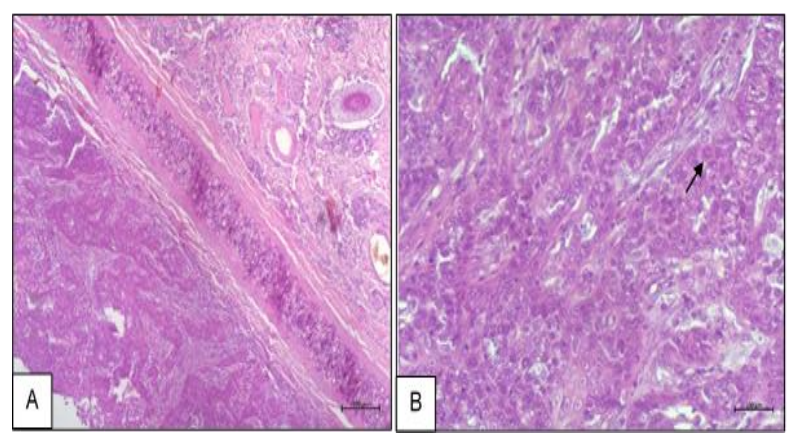

Figura 3. A. Aspecto geral microscópico da lesão, demonstrando em porção inferior extenso crescimento neoplásico perifericamente ulcerado, subjacente a cartilagem auricular e epiderme ainda preservadas (HE, 40x); B. Detalhes do padrão de crescimento maligno, salientando os blocos celulares malignos moderadamente differenciados e eventuais mitoses atípicas (seta) (HE, 200x).

Os gatos de pelagem branca são mais propensos a apresentar a doença que os pigmentados; nesses últimos, as lesões se desenvolvem em áreas com pouco pelo e sem pigmento. O tumor pode ser observado em gatos jovens, mas a média de idade é 11 anos e quatro meses (Ettinger \& Feldman 2004). No caso relatado, o animal apresentava todas as características que contribuíam para o surgimento da referente enfermidade, caso que era acentuado devido ao fato de se tratar de um felino irrestrito, assim, estando mais exposto à radiação solar. Embora não se tenha histórico quanto a idade do animal para o relato, pode-se supor que o animal era adulto e de idade avançada considerando a avaliação da dentição do mesmo, que apresentavase com áreas de bastante desgaste na arcada dentária já completamente preenchida.

O diagnóstico é geralmente baseado na anamnese, aliada a um exame físico detalhado, além da avaliação citológica de triagem (quando possível) e do exame histopatológico na confirmação do diagnóstico (Roza 2004). Em caso de tumores pouco diferenciados, é necessário fazer uso da imuno-histoquímica para discernir carcinomas epidermóides de outros tipos de carcinomas que podem afetar a aurícula (Rodaski 2008). No exame físico é possível fazer um diagnóstico presuntivo de um tumor de pele pela inspeção e pela palpação, sendo de fundamental importância para as lesões múltiplas o diagnóstico diferencial de outras alterações dermatológicas 
como as lesões hiperplásicas, granulomatosas, inflamatórias, imunomediadas e infecciosas, como nas lesões causadas por Leishmania spp. (Rodaski 2008; Daleck et al. 2016; Megid et al. 2016). No caso em questão, suspeitou-se de carcinoma devido à característica da lesão, optando-se pela realização do histopatológico por se tratar do exame confirmatório de eleição para tal condição.

Existem várias modalidades de tratamento para o carcinoma de células escamosas. As lesões pequenas e superficiais podem ser tratadas com cirurgia, radioterapia, hipertermia, criocirurgia, terapia fotodinâmica ou quimioterapia tópica. Em casos de lesões maiores, a cirurgia é mais eficaz e para lesões profundas e invasivas, opta-se por teleterapia com radiação ou quimioterapia intralesional (Ettinger \& Feldman 2004). No seguinte caso, devido ao estadiamento e a localização do tumor, o tratamento de eleição consistiu na remoção cirúrgica da parte lesada pela técnica de conchectomia. Assim, devido ao fato de o tipo tumoral descrito possuir baixo potencial de metastático, a conchectomia é uma terapia rápida e eficaz, fornecendo considerável sobrevida com mínima mortalidade quando realizados os procedimentos dentro do tempo e técnicas adequados (Jericó et al. 2015).

\section{Considerações finais}

Considera-se que o carcinoma é uma neoplasia maligna, no entanto de baixo potencial metastático na espécie felina para a descrita apresentação, acometendo principalmente animais de pelagem clara e de idade mais avançada, geralmente mais expostos à radiação solar. A confirmação precoce do diagnóstico é de fundamental importância para o sucesso no tratamento da enfermidade, sendo o exame histopatológico a principal ferramenta diagnóstica confirmatória. A cirurgia excisional precoce se constitui método fundamental na remoção de neoplasmas restritos a áreas facilmente operáveis, portanto, ressalta-se aqui a importância do diagnóstico precoce na remissão e cura tumoral, tendo como base a aproximação clínico-cirúrgica eficaz, amparando-se em conhecimentos clínicos espécie-específicos, epidemiológicos, cirúrgicos, terapêuticos e tumorais comportamentais.

\section{Referências Bibliográficas}

Bastos R.S.C., Farias K.M., Lopes C.E.B., Pacheco A.C.L. \& Araújo Viana D. 2017. Estudo retrospectivo de neoplasias cutâneas em cães da região metropolitana de Fortaleza. Revista Brasileira de Higiene e Sanidade Animal 11, 3953.

Daleck C.R., Fonseca C.S. \& Canola J.C. 2016 Oncologia em cães e gatos. Roca, Rio de Janeiro.

Ettinger S. \& Feldman E. 2004. Tratado de medicina interna veterinária: doenças do cão e do gato. Guanabara Koogan, Rio de Janeiro.

Goldschmidt M.H. \& Goldschmidt K.H. (2017) Epithelial and melanocytic tumors of the skin. In: Tumors in Domestic Animals (ed. by Meuten DJ), pp. 88-141. John Wiley \& Sons Inc., Ames, Iowa, USA.

Goldschmidt M.H. \& Hendrick M.J. 2008 Tumors of the skin and soft tissues. In: Tumors in Domestic Animals, Fourth Edition (ed. by Meuten DJ), pp. 45-117. Iowa State Press, Iowa.

Gross T.L., Ihrke P.J., Walder E.J. \& Affolter V.K. 2008. Skin diseases of the dog and cat: clinical and histopathologic diagnosis. Blackwell Science, USA.

Gross T.L., Ihrke P.J., Walder J.E. \& Affolter K.V. 2009. Doenças de pele do cão e do gato: diagnóstico clínico e histopatológico. Roca, São Paulo.

Jericó M.M., Kogika M.M. \& Andrade Neto J.P. 2015. Tratado de medicina interna de cães $e$ gatos. Guanabara Koogan, Rio de Janeiro, Brasil.

Megid J., Ribeiro M.G. \& Paes A.C. 2016 Doenças infecciosas em animais de produção $e$ de companhia. Roca, Rio de Janeeiro, Brasil.

Modiano J.F., Ritt M.G. \& Wojcieszyn J. (1999) The molecular basis of canine melanoma: pathogenesis and trends in diagnosis and therapy. Journal of veterinary internal medicine 13, 163-74.

Rangel M.M.M., Fernandes N.C.C., Nagamine M.K., Fukumasu H., Oliveira K.D., Lowe R., Mir L.M., Sinhorini I.L. \& Dagli M.L.Z. 2008. Eletroquimioterapia: uma nova promessa para o tratamento de cânceres em animais. Clínica Veterinária 13, 30-6.

Rodaski S. 2008. Quimioterapia antineoplásica em cães e gatos. MedVet Livros, São Paulo.

Roza M.R. 2004. Odontologia em pequenos animais, Rio de Janeiro.

Withrow S.J., Page R. \& Vail D.M. (2014) Ssmall animal clinical oncology. Elsevier Health Sciences, St. Louis.

License information: This is an open-access article distributed under the terms of the Creative Commons Attribution License 4.0, which permits unrestricted use, distribution, and reproduction in any medium, provided the original work is properly cited. 